\title{
AMADEO LLAVERÍAS Y LA BIBLIOTECA DEL GIMNASIO COLÓN (1892-1935). UNA VIEJA PUGNA EN TORNO A LA NACIONALIZACIÓN DE UNA BIBLIOTECA GIMNÁSTICO-DEPORTIVA
}

\author{
Xavier Torrebadella Flix* \\ Departamento de Didáctica de la Expresión Musical, Plástica y Corporal. Universidad Autónoma de Barcelona.
}

\begin{abstract}
Resumen: El objeto de estudio es indagar en las vicisitudes de la conocida biblioteca gimnástico-deportiva del Gimnasio Colón (1892-1906), recopilada por Amadeo Llaverías en Barcelona. Asimismo se analiza la trascendencia de esta biblioteca y del Catálogo del Gimnasio Colón (1935) en su época. A través de la revisión de los estudios anteriores y de nuevas informaciones obtenidas de fuentes primarias se profundiza en la crítica del expolio y el paradero de esta biblioteca después de la Guerra Civil española. Desde entonces hasta la actualidad, se aborda el desacuerdo institucional y el conflicto político en torno a la propiedad y custodia de los documentos catalogados por Amadeo Llaverías. Finalmente nos ocupamos del valor documental del citado catálogo y de los libros existentes para el estudio histórico de la educación física, el deporte y otras materias afines.

Palabras clave: Gimnasio Colón; Amadeo Llaverías; gimnástica; educación física; deporte; Barcelona; bibliografía deportiva.
\end{abstract}

Title: AMADEO LLAVERÍAS AND THE LIBRARY OF THE COLÓN GYMNASIUM (1892-1935). A LONGSTANDING STRUGGLE SURROUNDING THE NATIONALISATION OF A GYMNASTICS-SPORTS LIBRARY.

Abstract: This study investigates the vicissitudes of the well-known gymnastic-sports library of the Colón Gymnasium (1892-1906), compiled by Amadeo Llaverías in Barcelona. It also analyses the significance of this Library and of the Catalogue of the Colón Gymnasium (1935) in that period. Through a review of previous studies and by assessing new information obtained from primary sources, the study provides a deeper level of criticism regarding both the despoilment and the subsequent whereabouts of this library after the Spanish Civil War. From that period to the present, the study addresses the institutional disagreement and political conflict surrounding the ownership and custody of the documents catalogued by Amadeo Llaverías. Finally, the study focusses on the documentary value of this catalogue, and of the surviving books, for the historical study of physical education, sport and other related subjects.

Keywords: Colón Gymnasium; Amadeo Llaverías; gymnastics; physical education; sports; Barcelona; sports bibliography.

Copyright: (C) 2018 Servicio de Publicaciones de la Universidad de Murcia (Spain). Este es un artículo de acceso abierto distribuido bajo los términos de la licencia Creative Commons Reconocimiento 4.0 Internacional (CC BY $4.0)$.

\section{INTRODUCCIÓN}

La bibliofilia es una actividad libre que se remoza de romanticismo en la búsqueda de la rareza y del libro olvidado. De la bibliofilia a la bibliografía empírica y especializada existe un pequeño paso. Es Marcelino Menéndez (1876) con De re bibliographica quien conformó el primer trabajo teórico en donde se valoraba la importancia de los estudios bibliográficos ${ }^{1}$. En España, los bibliófilos tienen una larga tradición (Sánchez Mariana, 1993), y no es hasta la llegada de Rufino Blanco (1927), cuando esta materia adquiere propiedad científica para el estudio de la educación física y el deporte (Torrebadella-Flix, 2014).

El aprecio por los libros no ha sido siempre el mismo. Hubo épocas en que la destrucción generalizada de las obras fue masiva. Sobre esta cuestión se pronunciaba Antonio Palau (1982), el librero anticuario más importante que ha tenido Barcelona. Conociendo y viendo el expurgo, destrucción y expolio de las obras españolas, quiso emprender la comprometida y ardua labor de confeccionar un "Manual del librero hispanoamericano por orden alfabético de autores, anónimos y seudónimos, los libros, opúsculos, hojas y grabados, dignos de ser conservados y estudiados, impresos en España y en América latina" (Palau, 1982, p. X). Esta voluminosa obra representa hoy la más completa de las bibliografías retrospectivas nacionales.

\footnotetext{
*xtorreba@gmail.com

Recibido: 13-03-2017; 2 $2^{\mathrm{a}}$ versión: 22-01-2018; aceptado: 22-01-2018.
}

TORREBADELLA FLIX, X. Amadeo Llaverías y la biblioteca del Gimnasio Colón (1892-1935). Una vieja pugna en torno a la nacionalización de una biblioteca gimnástico-deportiva. Anales de Documentación, 2018, vol. 21, $\mathrm{n}^{\circ}$ 1. Disponible en: http://dx.doi.org/10.6018/analesdoc.21.1.288731. 
Era evidente la preocupación de Palau, un hombre de cultura, ante el menosprecio que algunos tenían por los libros viejos. Así comentaba que en el último tercio del siglo XIX:

Generalmente los libros que estaban en lenguas incomprensibles para los negociantes eran despojados de sus pergaminos y estos destinados a la fabricación de tambores y otras artes industriales. Una vez hecha esta operación se reunía todo el género inservible y se mandaba al molino de papel. Así desaparecieron para siempre, manuscritos, incunables, y otras preciosas tipografias, que eternamente echaremos de menos. (Palau, 1982, prólogo, p. V) ${ }^{2}$.

Otro suceso de la época fue la venta de libros amontonados, y a precios marcados de 10 céntimos a una peseta. Antonio Palau cuenta que hacia 1889, los libreros a tienda abierta vendieron verdaderos e ignorados tesoros a los feriantes de la calle: multitud de libros como morralla a 5 pesetas el saco. Entre estos libros se podían encontrar obras en letra romana y gótica, obras de Dante y Petrarca, manuscritos en vitela o primeras obras de Calderón de la Barca.

Las palabras de Antonio Palau no pueden ser más contundentes y tristes para la cultura española. Entre tantas obras perdidas, tesoros, seguramente también había aquellos libros que en nuestra rama del conocimiento -la educación física y el deporte-, hoy son tan difíciles de localizar.

En cada época las valoraciones al libro están sujetas a un significado cultural, social y político que identifican y condicionan la naturaleza y la vida de las obras (Torrebadella y Brasó, 2018). Así, por ejemplo, con el auge del movimiento gimnástico-deportivo, los libros de este campo no gozaron de un valor literario y científico, con lo cual las bibliotecas públicas no tuvieron interés en adquirir y conservar este tipo de obras (Torrebadella, 2013a; 2016; Torrebadella-Flix y Nomdedeu-Rull, 2014). Por otro lado, como apunta Pastor Pradillo (2008, p. 15), “desde la perspectiva propia de la bibliografía general, la educación física se sitúa siempre en un plano adyacente, de dudosa legitimidad y de escasa valoración científica" y, además, existe el poco interés que hasta ahora ha despertado entre los investigadores de la educación física y el deporte el estudio de la bibliografía del pasado.

El siglo XX fue también el siglo de las bibliotecas populares, gracias a las filantrópicas aportaciones o estudios bibliográficos que nacieron de denodados bibliófilos. Antes del siglo XX, las bibliotecas generalmente estaban al alcance de las instituciones pudientes (círculos literarios, artísticos y científicos), como el Ateneo de Madrid o el Ateneo Barcelonés; y otras bibliotecas menores se encontraban en colegios de religiosos, institutos de segunda enseñanza y en el círculo privado de las grandes fortunas. Así, por ejemplo, es preciso destacar la Biblioteca de Cataluña, creada en 1907 bajo el impulso del Instituto de Estudios Catalanes, y más tarde, a partir de 1914 engrandecida por la Mancomunidad de Cataluña.

Partiendo de esta realidad, existen también las bibliotecas particulares, que en su época algunos eruditos o instituciones fueron constituyendo, aglutinando libros y otros documentos en torno a un ámbito temático y, que hoy, han trascendido como valiosas colecciones especializadas de interés histórico y bibliófilo. Algunas de estas colecciones fueron registradas y expuestas a la luz pública, impresas como catálogos o bibliografías.

En el caso que aquí nos ocupa, no son muchos los catálogos y repertorios bibliográficos antiguos e impresos (es decir, antes de 1939) en torno a la materia gimnástica y deportiva que se destacan por su especial significación y valor documental (Blanco, 1927; Leguina, 1904; Llaverías, 1910, 1935; Museo Pedagógico Nacional, 1915; Palau, 1925; Torrecilla, 1921; Uhagón y Leguina, 1888).

De todos ellos, en este estudio nos vamos a ocupar de los catálogos publicados por Amadeo Llaverías, propietario del Gimnasio Colón (1892-1906) en Barcelona y de la maravillosa biblioteca que, en materia de gimnástica, deportes y otros temas afines, llegó a reunir este gimnasiarca y bibliófilo. Así pues, el objeto de estudio es desvelar los avatares históricos de esta biblioteca, abordar el análisis crítico del estado de la cuestión y alorar de forma significativa los catálogos publicados sobre la misma, así como el de los ejemplares que aún se conservan.

La metodología manejada se centra en considerar un estudio histórico-documental a partir de las fuentes primarias descubiertas recientemente. El análisis de contenido de los textos documentales objeto de estudio es asimismo confrontado con otros trabajos e investigaciones (Berasategui, 1998, 2008; Torrebadella, 2000a, 2011, 2013a). También son considerados otros documentos legislativos y administrativos recientes, que posibilitan ajustar el estado de la cuestión. Una interpretación positivista y constructivista sirve para emprender un análisis acerca de las vicisitudes y problemas de la citada biblioteca. 
Así pues, al conocer la obra gimnástico-deportiva del gimnasiarca Amadeo Llaverías y su interés bibliográfico y bibliofílico en la materia, profundizaremos en el significado e importancia de la Biblioteca del Gimnasio Colón (BGC) y de la publicación de sus catálogos.

\section{LA GIMNASIA PARA LA CLASE OBRERA}

El 5 de mayo de 1892 Amadeo Llaverías Rovirosa (1871-1935) inauguraba en Barcelona el Gimnasio Colón (calle de san Pablo, 111), establecimiento que venía a unirse a los otros tantos gimnasios con los que contaba la ciudad (Torrebadella y Arrechea, 2015) [Imagen 1]. En este gimnasio Llaverías trató de transmitir la propaganda de la gimnástica higiénica entre la clase obrera (Llaverías, 1896). Para ello realizaba desde sus dependencias concursos y certámenes deportivos, gimnásticos y literarios. "Así que su gimnasio lo convierte a menudo en exposición, museo, biblioteca, sala de lectura, de baile, de concierto, y si me apuran hasta lo convertiría en plaza de toros, teatro o fortaleza, si creía que así iba mejor en aquel punto a practicarse su deporte favorito" (J. LL., 1902, p. 555). Hay que destacar el certamen literario de 1906 cuya temática giraba alrededor de la educación física, y que solamente podían participar aquellos profesores de gimnástica con título oficial que hubiesen publicado alguna monografía al respecto. El gimnasio se comprometía a publicar el artículo premiado (Llaverías, 1905b).

Las clases de gimnástica tenían unos precios bajos, para que fuesen asequibles a todo tipo de gentes. Del mismo modo que otros colegas suyos, Llaverías ofreció el gimnasio y su persona con objeto de impartir la asignatura de Gimnástica en algunos de los colegios de Barcelona, entre estos la Academia de Alfonso X, agregada al instituto (Miscelánea, 1900). Puede decirse que el Gimnasio Colón era un completo ateneo gimnástico en el que también se cultivaba el excursionismo, que comenzaba a ponerse de moda en Barcelona. Por otro lado, Llaverías fue un asiduo colaborador en la revista Los Deportes (1897-1910), que destacaba en detallar los pormenores de los gimnasios en Cataluña. Asimismo, en 1902 ocupó el cargo de secretario de la Federación Catalana de Gimnástica.

Era Llaverías un notable atleta, dotado de una cultura nada vulgar. Bajo su dirección acertada se formaron acróbatas, saltadores, atletas y hasta aeronautas. Llaverías en su juventud se exhibió en circos y plazas de toros, realizando proezas acrobáticas que le valieron el aplauso de todos los públicos.

Además de Barcelona, sede de sus triunfos, donde actuó en Fornos, Alcázar Español, Teatro Olimpo en varias sesiones, trabajó en diversas poblaciones de Cataluña. Pero no era de su gusto exhibirse en público y prefirió dedicarse a la enseñanza. (...)

Poseía Llaverías, además de una fuerza poco común, de una ligereza asombrosa y de un don especial para descubrir futuras glorias de la pista, grandes aptitudes para la esgrima, habilidad en el patinaje y conocimientos del baile atlético. Era, además, un ameno conferenciante y un buen organizador de festejos. (Dalmau, 1947, p. 47).

Llaverías y Antonio Palau y Dulcet (1867-1954) fueron íntimos amigos y a través de las memorias de este último conocemos aspectos de la vida del primero (Palau, 1935). En 1907, falleció su padre Juan Llaverías Sendra, que ejercía las funciones de director del gimnasio. En 1908 Amadeo se fue a Figueras para obtener el título de Bachillerato, que alcanzó en 1915 (Guardiola, 1955). Allí entre 1912 y 1916 estableció y dirigió otro excelente gimnasio particular con el mismo nombre que el anterior y también se dedicó a exponer libros sobre deportes (Llaverías, 1927; Palau, 1935). Posteriormente fue nombrado profesor del Instituto de Figueras (1909-1917). Luego continuó su formación hasta alcanzar en 1924 el título de profesor de Gimnástica en Madrid (Berasategui, 1998, 2008; Fusté, 1997; Palau, 1935). 


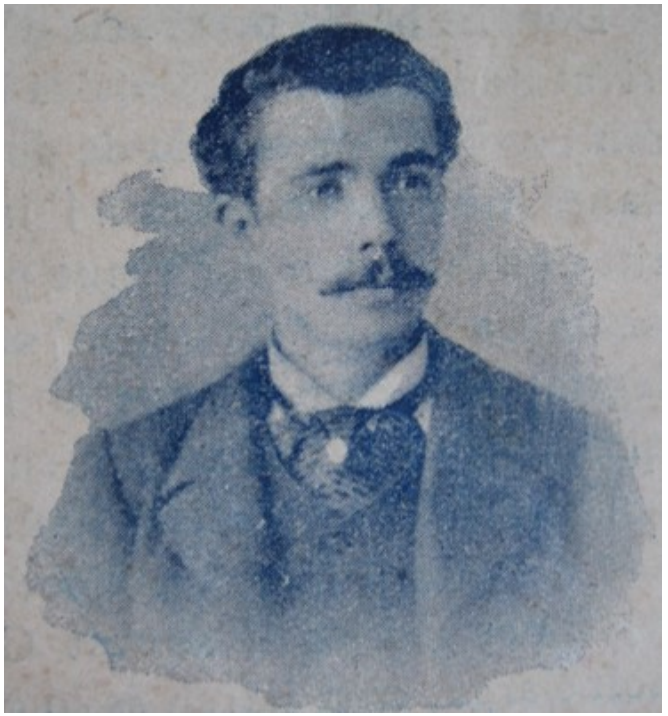

Imagen 1. Amadeo Llaverías, director del Gimnasio Colón (1896). Fuente: Autor.

El Gimnasio Colón ofrecía la posibilidad de ejercitar los métodos de Ling y de Amorós, pero se destacó en la práctica de la gimnástica deportiva, objetivo principal del establecimiento. En aquella época, David Ferrer (1899) consideraba la gimnástica artística bien dirigida como un deporte que no tenía peligros y al que en el futuro habría que prestarle una mayor atención. Sobre este tipo de gimnástica se comentaba que para Llaverías:

Eso de la gimnástica higiénica le parece a él cosa de lujo, y es partidario del atletismo neto y pelado, del salto mortal, de sostener una casa con los dientes, de molinetear en la barra fija, de equilibrarse en un alambre, es decir, de todo lo que se llama gimnasia artística en que el gimno es el todo y el arte lo de menos. (J. LL., 1902, p. 555).

Como se desprende del reglamento de 1901, el gimnasio disponía de un buen surtido de aparatos: trapecios de equilibrios, trapecios de vuelos, anillas, cuerdas, perchas, caballete ortopédico, escalera ortopédica, banco de pesos, escalera de mano, tablero, batuta, doble trapecio, aparatos de nuca, alambre, escalera de dobles equilibrios, correa de rotación, muelles, dentales, estafas, triángulo, trampolín, maroma, barra fija, aparatos de saltos, subida de puñales, pesas Sandow, sillas, dinamómetro, aparatos de goma, objetos de malabares y, posiblemente, algunos otros más (Llaverías, 1901).

Llaverías también creó una compañía internacional de variedades y de propaganda gimnástica, compuesta por quince alumnos que actuaron por primera vez en el Teatro de Lope de Vega (Miscelánea, 1901). Arturo Masriera cuenta lo importantes y considerados que fueron los gimnasios de la Barcelona de finales del ochocientos:

La afición a la gimnasia deportiva e higiénica arraigó desde entonces más y más y entre todas las clases sociales aparecieron atletas, acróbatas y luchadores de greco-romanos (o por lo menos, titulados tales), que, además de brillar en los respectivos gimnasios de donde eran alumnos, se atrevían a veces a tomar parte en los espectáculos de circo. Entre ellos figuraba la sesión anual que para conmemorar la solemnidad que a ellos mejor parecía, se destinaba a la vez a exhibir progresos y aptitudes de cada alumno. Médicos eminentes actuaron de atletas esforzados, escribanos y arquitectos hubo que hicieron prodigios levantando pesos colosales; cierto abogado reusense, después Presidente de la Diputación, daba el salto de corvas, colgado en la barra fija, con pasmosa rapidez; el que escribe, ejecutaba el vuelo mortal, lanzándose al aire de un trapecio a otro, y no faltaron comerciantes, militares y futuras glorias de la Iglesia, que en sus mocedades, acreditaron con aplauso unánime del público, sus habilidades gimnásticas. De estos ejercicios y sus sesiones nacía una cordialidad de relaciones y amistades que no es posible dar olvido, después de medio siglo de su nacimiento. El cuerpo se vigorizaba, el ánimo se tornaba más apacible y risueño, la higiene, la sobriedad y la agilidad salían siempre triunfantes, y los que no vivíamos esclavos de una vida sedentaria desconocíamos el mal humor y las enfermedades. Al que no era constante en acudir a tales ejercicios, le mirábamos con cierto desdén, y hasta, si los abandonaba, nos permitíamos considerarle como un ser inferior y de pocos bríos.

Más tarde, se desarrolló más y más en Barcelona este ejercicio, tan necesario a todas las profesiones y edades... (Masriera, 1924, p. 37-41). 


\section{LA BIBLIOTECA DEL GIMNASIO COLÓN}

Desde el primer momento, Llaverías se propuso formar una importante biblioteca especializada, única de su rango en toda España. La biblioteca ubicada en el mismo gimnasio estuvo abierta al público [Imagen 2]. El 26 de agosto de 1905 publicó en Los Deportes un catálogo de esta biblioteca, indicando que podía ser consultada todos los días, de 12 a 15 y de 19 a 22 horas (Llaverías, 1905a). Sin embargo, no sabemos por qué en noviembre de 1905 la BGC dejó de ser pública. La BGC era especialmente genuina, puesto que recopilaba centenares de obras (y otros numerosos documentos), en torno a la educación física, gimnástica, deportes y otros tantos temas afines. En sí se trataba de una esperada biblioteca gimnástico-deportiva.

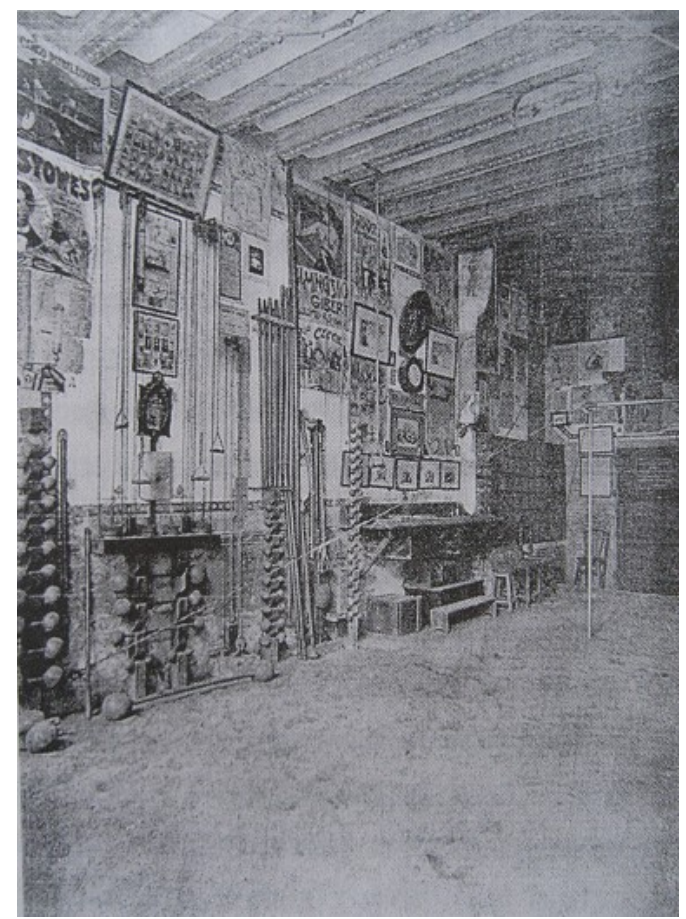

Imagen 2. Interior del Gimnasio Colón.

Hay quienes se interesaron por destacar el valor de esta biblioteca, como el profesor de Gimnástica Eusebio Ferrer del instituto de Palma de Mallorca. Desde Los Deportes, Llaverías respondía a este profesor sobre el contenido de la misma, indicando que no todos los títulos eran de gimnasia:

Alli hay ciencia y distracción para rato; pedagogía, fisiología, terapéutica, anatomía, fisica, hidroterapia, antropometría, mecánica, higiene, táctica militar, extinción de incendios, libros de primera enseñanza, diccionarios, manuales de conversación, catálogos de librería, de bibliotecas y de comercios y establecimientos industriales, fábricas de aparatos de gimnástica, etc.

Folletos, libros de premio, de juguete y con figuras de movimiento, cuentos, novela, ópera, zarzuela, comedia, música, manuscritos, historia, almanaques, reglamentos, libros anunciadores, mesa revuelta, memorias, argumentos de teatro, temas, propagandas, tesis de doctorado en medicina, juegos infantiles, de agilidad, de destreza y otros.

Periódicos sueltos y también colecciones de un año y otras completísimas, libros para el aprendizaje el colorido, álbums, impresos varios, poesía, lucha, boxeo, habilidades y entretenimientos varios, reseñas, métodos, prospectos, comprobantes, libretas y otros. Algo le masaje, ortopédica, educación, sport en general, natación, lawn-tennis, esgrima, patinaje, vela y remo, ciclismo, gimnástica acrobática, gimnástica mecánica, etc. (Llaverías, 1904, p. 704).

Antonio Palomo presentaba en Los Deportes un bosquejo de los tesoros que contenía la BGC, de la que decía estar metódicamente ordenada:

Pero lo que verdaderamente nos causó gran asombro haciéndonos palidecer de envidia fue la verdadera avalancha, y valga la frase, de tratados cientificos debidos a la pluma de las mayores reputaciones mundiales y con lo cual nos dejó convencidos una vez más el Sr. Llaverías de lo vasta y bien organizada que se halla su 
biblioteca, en la cual vimos figuran también en unión de manuscritos sueltos y selectos volúmenes, trabajos inéditos de los más concienzudos escritores que a la ardua tarea de ilustrar a los profanos en el ramo de la educación fisica se dedica. (Palomo, 1905, p. 833).

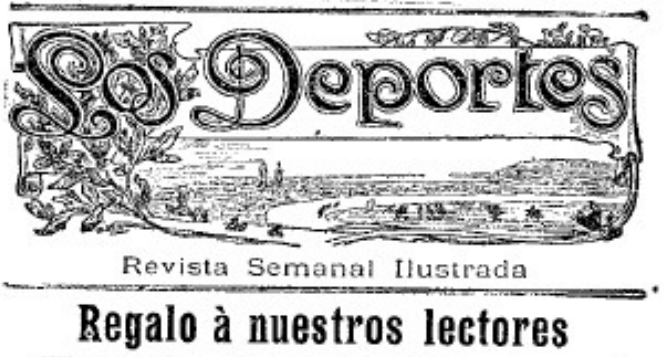

Tiempo ha, que obran en nuestro poder una nutrida colección de obras científicas, artísticas, y literarias, procedentes de la extinguida biblioteca circulante del Gimnasio Colón, cedidos por su antiguo profesor y dueño Sr. Llaverías.

Siguiendo nuestra campaña de difusión de los conocimientos útiles, regalaremos un ejemplar á todos los que se presenten en la calle de Valencia, 200; bajos (imprenta de Los Deportes») acompañando el talón que publicaremos en la sección de anuncios la semana próxima.

Imagen 3. Los Deportes, 13 de octubre de 1906, p. 710.

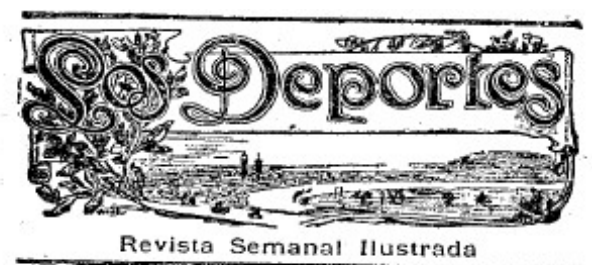

Regalo à nuestros lectores

Desde el dia 22 hasta el 27 del corriente y horas de 9 á 13 y de 15 á $18^{\prime} 30$ se regalará un libro, á elegir entre varios de los que figuraban en la que fué Biblioteca Circulante del Gimnasio Colón de Barcelona, á todos los que se sirvan presentarse con un ejemplar de este número en la imprenta de Los Deportes que se halla establecida en la calle de Valencia, 200, interior (entre Muntaner y Aribau).

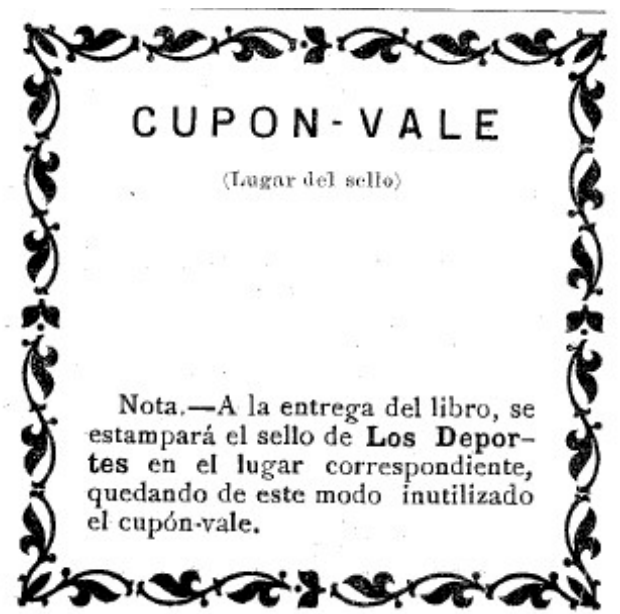

Imagen 4. Los Deportes, 20 de octubre de 1906, p. 734.

El 11 de noviembre de 1906 el Gimnasio Colón cerró definitivamente las puertas y la biblioteca fue alojada en las dependencias de Los Deportes (Berasategui, 1998; Fusté, 1997). Con esta decisión, Llaverías anunciaba posponer el proyecto de una "Biblioteca gimnástica nacional" (I., 1906, p. 972). A partir de aquí, el destino de muchos de los ejemplares es muy incierto. En Los Deportes se divulga el extraordinario contenido de la BGC, algunos aficionados a la gimnástica ya lo conocían, y otros se preguntaban sobre su utilidad pública. Lo extravagante fue la decisión de una campaña promocional de la revista (Los Deportes, 1906b, 1906c), que aprovechó los ejemplares de la "biblioteca circulante del Gimnasio Colón" para obsequiar a los subscriptores (Torrebadella, 2016) [Imagen 3 y 4]. Asimismo, cabe la posibilidad de que algunos de los ejemplares de la biblioteca fuesen obsequiados por Llaverías al Club Natación Barcelona, entidad que también proyectaba una biblioteca deportiva (Miscelánea, 1908). 
En 1906 desde las páginas de Los Deportes se mencionaba que en las librerías de Barcelona ya se podían adquirir algunas obras de gimnástica. No obstante, se echaba en falta la divulgación de obras más populares (Los Deportes, 1906a).

Después de esta locura de regalar libros se procedió al almacenamiento del resto de las obras y, años más tarde, se procedió a la impresión del catálogo (Llaverías, 1910). Desde entonces, y durante quince años, la BGC permaneció expuesta a la venta. Aun así, Llaverías (1910) insistía en la necesidad de proporcionar un amplio compendio bibliográfico en el campo de las prácticas gimnásticas y deportivas. Así proponía una clasificación por temas para organizar una completa bibliografía deportiva: gimnasia, acrobacia, deportes, auxiliares del deporte, juegos deportivos, conocimientos afines y materiales diversos.

No existe, hasta la fecha, ninguna bibliografia de gimnasia en general; solo sí de esgrima, caza, aeronáutica y nada más. Se han asimismo publicado algunos catálogos especiales de materias deportivas, tanto por parte de editores como de libreros de lance o anticuarios.

Estos catálogos apenas contienen nada y están huérfanos de muchas variantes que dentro de la bibliografía deportiva hace años gozan de completa autonomía. Tienen además, tales catálogos, el inconveniente de que se les atiborra de asuntos extraños a los que nosotros llamamos deporte, como por ejemplo: cartomancía, adivinación, magia, hipnotismo, prestidigitación, nigromancia, ciencias ocultas, juegos de azar, jardinería,... (Llaverías, 1910, p. 8).

Como alude Berasategui (2008), Llaverías años más tarde en La Veu de l'Ampordá continuaba manifestando: "Respecto a deportes o, mejor dicho, a cultura física en general no existe aún ninguna bibliografía. Monografías bibliográficas sí que más o menos las hay. Especialmente de caza, equitación, esgrima y aeronáutica" (Llaverías, 1917a, p. 3). En este caso, Llaverías se ocupaba de criticar la publicación del Museo Pedagógico Nacional (1915), sobre Bibliografía y material de enseñanza, Educación física. - Higiene escolar, comentando la ausencia de numerosas obras deportivas (en total 39), que ya había expresado anteriormente y que, en esta ocasión, añadía las referencias completas de otros 20 títulos más. Unos días más tarde, Llaverías volvía a replicar ofreciendo una "bibliografía gimnástica" y el modo en cómo clasificaría la amplitud de todos los títulos existentes y materias afines.

Dejando por esta vez las frondosas ramas del tronco gimnástico: acrobacia, deportes y sus auxiliares, juegos de la infancia, juegos deportivos; así como algunos conocimientos afines: existen de incendios, salvamento, etc., etc., y concretándose al habla castellana, las obras, folletos, revistas de gimnasia (médica, higiénica y sesenta denominaciones más) aparecidas hasta la fecha en dicho idioma suman muy cerca de 400, no incluyendo en este número las distintas ediciones. (Llaverías, 1917b, p. 2).

Además, Llaverías ofrecía la muestra de una selección de doce asientos bibliográficos, muy bien estructurados, con noticias sobre las obras. Véase al caso un ejemplo:

MERCURIALI (Girolamo).-Dell' arte ginnastica. Libri sei. Recati per la prima volta in italiana favella dal sacerdote Giovanai Rinaldi da Forli. Con note. Faenza, Conti, MDCCCLVI, in-4. ${ }^{\circ}$ mayor, láms. y 1 grabado. Contiene además el retrato y biografía del autor. Existen de esta obra 7 ediciones en latín y una en castellano: Madrid, 1845. (Llaverías, 1917b, p. 2).

En La Veu de l'Ampordá Llaverías continuó ofreciendo una estrecha y asidua colaboración prácticamente hasta el último año de vida. Publicó numerosos artículos de gimnástica, deportes, sobre bibliofilia, bibliografía y biografías, y otros tantos temas culturales, siempre interesantes (Palau, 1935).

Ya hemos mencionado que en 1910 Llaverías publicó un primer Catálogo de la biblioteca del Gimnasio Colón con una aportación de 1.021 referencias (Llaverías, 1910). Este catálogo recoge obras de diversa índole, aunque, sobre todo, se destacan las relacionadas con la actividad física: educación física, gimnástica, deportes, juegos corporales o circo. Las obras corresponden a diferentes formatos: libros, revistas, catálogos, folletos, talonarios o almanaques. Podemos encontrar obras en varios idiomas: alemán, sueco, francés, ruso, búlgaro, griego, turco o japonés.

En 1921 se trataba en la revista Stadium el futuro de la BGC y, a la vez que se presentía el riesgo de perder tan valioso legado, se pedía la protección:

Llaverías no es joven y está expuesto como cualquiera a desaparecer. ¿Qué será entonces de esta biblioteca? ¿Dónde irán a parar esos rarísimos libros y estampas, de revistas y diarios, de programas y folletos?

Creemos que la biblioteca de sports debería figurar en el lugar adecuado, enriqueciendo el valioso caudal del Instituto de Estudios Catalanes. Los dos obstáculos que deben vencerse pueden eliminarlos, con relativa 
facilidad, los deportistas, aportando su concurso para que pueda realizarse la adquisición, e imponiendo, el ceder la biblioteca, la condición de que sea Llaverías bibliotecario honorífico, para que así pueda llevar a cabo su alto ideal que se impuso al clasificar las valiosas rarezas que fue juntando con una unción tan grande, tan sublime, tan sin igual. (Saudades, 1921, p. 734).

En esta época algunas voces de aficionados a los deportes pedían tanto a la Biblioteca Nacional como a la Biblioteca de Cataluña, disponer de una mayor presencia de obras deportivas para su consulta (Torrebadella-Flix y Nomdedeu-Rull, 2014).

Años más tarde aparecieron la mayoría de las obras del catálogo de 1910 expuestas en el Catàleg núm. 27: Esgrima, Caça i Pesca, Hipisme, Jocs, Esports, Gimnástica, tauromaquia, Dansa, etc., etc., de la Librería Anticuaría que Antonio Palau disponía de en la calle Sant Pau, 41. En este catálogo Palau incorporó un total 1.149 obras referenciadas de la biblioteca del Gimnasio Colón de Barcelona y de Figueras, que ya ponía a la venta por un precio de 20.000 pesetas, tal como mencionaba (en idioma francés) en la contraportada (Palau, 1925). Lo que no sabemos es si Antonio Palau ya compró la colección a su amigo Llaverías en esta época. Palau era un bibliófilo y, profesionalmente, un librero, pero también era amigo íntimo de Llaverías.

En este catálogo de 1925, las obras (libros) que podemos clasificar en torno a las actividades gimnástico-deportivas son 72 obras sobre esgrima, 75 obras sobre caza y pesca, 110 obras sobre hipismo, 92 obras sobre juegos, 73 sobre deportes y gimnasia. Entre estas 422 obras, muchas de ellas en francés, se localizan 66 obras en castellano, la mayoría del siglo XIX -55 obras-, que se reparten entre: 21 obras de gimnasia, 19 obras de esgrima, 14 obras de equitación y el resto de obras se hallan repartidas entre pelota, natación, velocipedismo, baños, aviación, juegos, caza y ju-jutsu [sic].

Al cabo de un cuarto de siglo del primer Catálogo de la biblioteca del Gimnasio Colón (esto es mucho tiempo), Antonio Palau ofreció la publicación del Catálogo de la biblioteca del Gimnasio Colón (1910 - $1^{\mathrm{a}}$ parte- y $1935-2^{\mathrm{a}}$ parte), esta vez con un total de 2.917 documentos catalogados, supuestamente todos ellos pertenecientes a la BGC. Así, la catalogación fue terminada por el prestigioso bibliógrafo y amigo de Llaverías:

Hasta aqui la catalogación de nuestro malogrado amigo Amadeo Llaverías, impresa por Fiol en la calle san José, en 1910. Cuando Llaverías se hizo el propósito de conquistar el título oficial de Profesor de Gimnasia, resolvió estudiar en el Instituto de Figueras. Por consiguiente, acomodó los ejemplares de estos ocho pliegos, hasta entonces impresos, en una caja que llevó consigo a la capital del Ampurdán y allá permanecieron hasta su regreso definitivo a nuestra ciudad en 1917. Desde entonces Llaverías venía persiguiendo la ilusión de terminar el catálogo de su biblioteca, pero el 8 de enero del presente, le sorprendió la muerte, sin haber realizado su ideal. Fiel a mi entrañable amistad con él y en el justo homenaje al amigo, completo el presente catálogo. (Llevarías, 1935, p. 129).

Como es lógico, Palau continuaba vendiendo la BGC, incluso manteniendo el mismo precio que ya había marcado en 1925: "Esta biblioteca compuesta de 2.917 números, vale actualmente en comercio 24.000 pesetas, su propietario la había tasado en 20.000 pesetas. Nosotros la cedemos por 14.000 pesetas, y sí la venta se efectúa al contado rebajamos un 10\%" (Llaverías, 1935, cubierta) [Imagen 5]. 


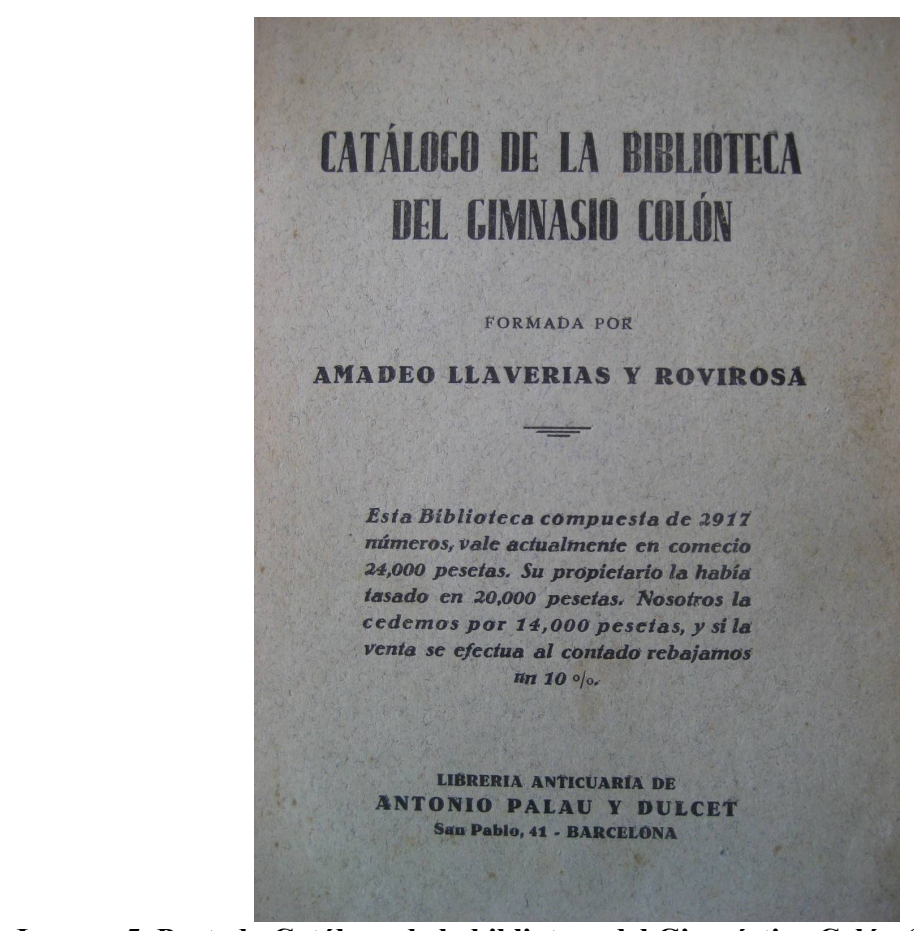

Imagen 5. Portada Catálogo de la biblioteca del Gimnástico Colón (Llaverías, 1935).

Años más tarde, la Academia de Educación Física de Cataluña pedía a la Biblioteca de Cataluña una sección destinada a preservar obras de cultura física y deportiva para el estudio de los aficionados (Torrebadella, $2013 b$ ). Ciertamente cuando se constituyó el Instituto Nacional de Educación Física de Cataluña, faltaba una biblioteca y, por lo tanto, puede que este fuera el motivo de la compra de la BGC que hizo efectiva el Comisariado de Educación Física y Deportes de la Generalitat en 1937 (Berasategui, 2008; Pujadas y Augué, 2013; Torrebadella, 2000b).

Finalmente, en tiempos de la Guerra Civil la BGC fue comprada por el Comisariado de Educación Física y Deportes. Como es conocido, con la ocupación final de Barcelona por las tropas franquistas, la BGC fue requisada y cedida al Comité Olímpico Español, ocupándose luego de ella la Delegación Nacional de Deportes e integrada posteriormente en la Biblioteca Deportiva Nacional del Instituto Nacional de Educación Física y Deportes (INEF) de Madrid (Berasategui, 1998, 2008; Fusté, 1997; Piernavieja, 1973a; Torrebadella, 2000a, 2009, 2011).

En el Manual del librero hispanoamaricano Antoni Palau introdujo una nota de aclaración sobre el paradero de la BGC:

Esta biblioteca, puede que única en España en materia de Sports, fue vendida por el que esto escribe, a la Generalitat de Cataluña, en 1937. A principios de 1939, el camarada Josep Mesalles Estevill, secretario de la Delegación Nacional de Deportes de F.E.T y de las J.O.N.S., la transportó al local del Comité Olímpico Español, hoy Ferraz 16, Madrid. (Palau, 1982, núm. 144869).

Efectivamente, la colección fue adquirida en un primer lugar, por la Generalitat de Cataluña (Comisariado de Educación Física y Deportes, 1937), que tenía la intención de crear una biblioteca pública deportiva y, en 1939 retenida por el Comité Olímpico Español (COE). Finalmente, como cuenta Miguel Piernavieja (1973a), director del Centro de Documentación e Información del Instituto Nacional de Educación Física de Madrid (INEF), en 1967 gran parte de la colección fue destinada al INEF. Naturalmente, el instruido Piernavieja conocía la verdad y, por eso, no podía esconder la autenticidad de una colección, cuya procedencia era perfectamente testimoniada por Antonio Palau (Berasategui, 2008). Con lo cual, el director del Centro de Documentación e Información del INEF sabía que todos esos libros, de "gran valor comercial y bibliófilo" que se habían concentrado repentinamente en Madrid, procedían de la BGC:

Suponemos con cierto fundamento, que había sido adquirida por la Generalitat de Cataluña al barcelonés Gimnasio Colón, uno de los pioneros de la educación física en España... De alguna manera la biblioteca fue a parar al Comité Olímpico Español antes de 1939, pues en los pocos ejemplares llegados a Madrid procedentes del Comité aparece con frecuencia el sello de la Generalitat de Cataluña y hasta con la correspondiente clasificación decimal, prueba del esmero con que fueron tratados. (Piernavieja, 1973a, p. VIII-IX). 
Piernavieja (1973a, p. IX) añadía (supuestamente por no entrar en conflicto) que el "traspaso o cesión de libros de la Generalitat al Comité Olímpico Español es un suceso cuyas razones desconocemos”. Asimismo, Piernavieja comentó que no se conserva registro escrito de la personalidad jurídica que realizó la compra del catálogo de la BGC.

Sin duda alguna, el traslado de la BGC a Madrid fue un caso más del expolio, tal y como se condena en el Congreso de Diputados (2005b) -o "botín de guerra"- generalizado de la documentación propiedad de la Generalitat de Cataluña y de otras instituciones catalanas que durante la Guerra Civil realizó el bando sublevado contra la II República (Berasategui, 2008; Cruanyes, 2002, 2003; Serramià, 1997; Torrebadella, 2009). Sobre este asunto, Cruanyes destaca el secuestro generalizado a cargo de la Delegación de Estado para Recuperación de Documentos (DERD) de bibliotecas públicas y librerías y, posteriormente, la destrucción sistemática de las obras, cuya intención después de ser empleada con finalidades represivas- no era otra que la de borrar cualquier rastro de memoria histórica de la autonomía de Cataluña:

A lo largo de la historia el botín ha representado un símbolo del triunfo sobre el vencido. Si no tuviera este significado, no se entendería que, el material intervenido, además de documentos, libros y publicaciones, contuviera también banderas y sellos de entidades. (Cruanyes, 2002, p. 63).

Sobre el retorno completo de la BGC, en la actualidad, no consta que la Generalitat de Cataluña mantenga abierto litigio alguno. No obstante, el caso se conoce y se divulga en Cataluña con el propósito de recabar esfuerzos en la recuperación de este fondo bibliográfico (Casas, 2005).

Por otro lado, existe el informe del Relator Especial de Naciones Unidas sobre la promoción de la verdad, la justicia, la reparación y las garantías de no repetición (De Greiff, 2014, p. 22), que en el caso de España insta que se tomen medidas "para atender los pedidos relacionados con la restitución de las propiedades y documentos incautados a particulares".

El problema ya ha sido reconocido oficialmente por parte del Gobierno español, a instancias parlamentarias de los partidos catalanes, en el Congreso de Diputados (2005b). Aun así, sobre este asunto, las instituciones implicadas parece que no desean comprometerse o hablar demasiado.

\section{DISPUTAS POLÍTICAS RELATIVAS AL TRASPASO DEL FONDO DE LA BGC}

En 1981 la Dirección General de Deportes de la Generalitat de Cataluña puso en conocimiento del Consejo Superior de Deportes los antecedentes del fondo de libros procedentes del Comisariado de Educación Física y Deportes, y solicitó su devolución sin éxito alguno.

El 21 de noviembre de 1983 se reunieron en el Palau de la Generalitat de Cataluña (Barcelona), de una parte, el Presidente de la Generalitat de Cataluña, Jordi Pujol i Soley, y de la otra el Secretario de Estado para el Deporte, Romà Cuyàs i Sol, en representación del Consejo Superior de Deportes. Se aprobó, en convenio firmado por ambas partes, la devolución de todos los libros a sus "legítimos titulares, es decir, a la "Generalitat de Cataluña" a través de la Dirección General de Deportes". Asimismo, se hacía entrega de 230 obras del fondo bibliográfico del INEF procedentes de la Biblioteca Nacional Deportiva (obras del antiguo fondo de la BGC), con el sello del Comisariado de Educación Física y Deportes, a la Biblioteca de Deportes de la Generalitat de Cataluña. En su apartado segundo del citado convenio se menciona que "con esta fecha y a todos los efectos se efectúa formalmente la entrega del citado fondo a la Generalitat de Cataluña mediante 'traditio' de la relación de libros y títulos ya identificados" (Oficina de Registro e Información de la Secretaría General del Consejo Superior de Deportes, 2016a).

Asimismo, se creó una comisión técnica para el estudio e identificación de las obras del Comisariado de Educación Física y Deportes depositadas en el fondo bibliográfico del INEF, "para el posterior traspaso de las obras pendientes" (Generalitat de Cataluña, 1983, p. 1). La comisión parece que censó doscientas diez obras más y otras cinco con algunas incidencias. A raíz de esta comisión (y de otras reuniones técnicas entre ambas administraciones) se elaboraron borradores de convenio, uno de ellos en 1996 entre el Secretario de Estado, Pedro Antonio Martín Martín (del Partido Popular), y Fidel Sust i Mitjans, Secretario General de Deportes de la Generalitat de Cataluña, donde se reconocía la cesión de los volúmenes demandados (Congreso de los Diputados, 2005b).

Con este convenio, el Gobierno socialista de Felipe González reconocía el expolio de los libros y la deuda pendiente a su legítimo propietario, la Generalitat de Cataluña. 
Pasan los años y los libros cotejados aún siguen sin traspasarse. El problema se enquista en 1998 con la integración del INEF en la Universidad Politécnica de Madrid (UPM) (Decreto 155/1998). En dicho decreto de integración y en la documentación aneja, no figura mención patrimonial alguna a ningún asunto pendiente por parte del INEF, por lo que "la UPM actualmente no tiene constancia de que haya ningún contencioso abierto al respecto" (Facultad de Ciencias de la Actividad Física y del Deporte, 2016).

Efectivamente, el traspaso del INEF a la UPM (Comunidad Autónoma de Madrid) se produjo durante el Gobierno del Partido Popular con el apoyo de Convergencia i Unió, cuando este último también gobernaba en Cataluña. En este traspaso no se tuvo en cuenta el asunto pendiente de los libros, ya fuere por cuestiones políticas o por simple olvido.

El 28 de septiembre de 2004, Josep Maldonado i Gili, diputado por el grupo parlamentario de Convergencia i Unió, presentó una interposición acerca de las "Previsiones acerca de devolver a Cataluña el Archivo Histórico del Comissariat d'Educació Fisica i Esport de la Generalitat de Cataluña del período de la II República, que está depositado una parte en el Instituto Nacional de Educación Física (INEF) de Madrid (Congreso de los Diputados, 2004, p. 189). La respuesta del Gobierno de España fue la siguiente:

En el Consejo Superior de Deportes no hay actualmente constancia documental del Archivo Histórico del Comisariado de Educación Física y Deportes de la Generalitat de Cataluña, correspondiente al período de la II República española.

Este hecho se debe a que el Instituto Nacional de Educación Física (INEF) de Madrid fue transferido a la Comunidad Autónoma de Madrid por Real Decreto 1192/1998, de 12 de junio, por lo que el Consejo Superior de Deportes no puede realizar ninguna previsión al carecer de titulación patrimonial sobre sus depósitos documentales.

Madrid, 14 de diciembre de 2004.- El Secretario de Estado de Relaciones con las Cortes. (Congreso de los Diputados, 2005a, p. 72).

Ante la insatisfacción, los grupos parlamentarios catalanes presentaron dos proposiciones no de ley. La primera era "Relativa al traspaso a la Generalitat de Cataluña de los fondos de la Generalitat republicana localizados en la biblioteca del Instituto Nacional de Educación Física (INEF) de Madrid, presentada por el grupo parlamentario catalán (Convergència i Unió) (número de expediente 161/000590)". La segunda proposición aludía a la condena del "expolio bibliográfico padecido por la Comisaría de Educación Física y Deportes de la Generalitat de Cataluña a manos del gobierno del General Francisco Franco, presentada por el grupo parlamentario de Esquerra Republicana (ERC) (número de expediente 161/000645)" (Congreso de los Diputados, 2005b, p. 17). Ambas proposiciones no de ley fueron aprobadas en votación en los términos de la enmienda transaccional presentada conjuntamente por los grupos Socialista, Convergència i Unió, Esquerra Republicana e Izquierda Verde-Izquierda Unida-Iniciativa per CataluñaIzquierda Unida-Verds (votos a favor, 22; abstenciones, 15).

Después de ambas proposiciones, los libros que pertenecían al Catálogo del Gimnasio Colón aún siguen depositados en la biblioteca del INEF de Madrid. Las voluntades en responder sobre el asunto son dilatorias y esquivas, tal y como evidencia el siguiente comunicado, que hace referencia a la petición de visualizar el convenio de 21 de noviembre de 1983, firmado por la Generalitat de Cataluña y el Consejo Superior de Deportes: "En respuesta a su mensaje, recibido a través del formulario de contacto de la web del Consejo Superior de Deportes, le informamos que la unidad depositaria de dicho convenio es la Dirección General de Deportes de la Generalitat de Cataluña" (Oficina de Registro e Información de la Secretaría General del Consejo Superior de Deportes, 2016b).

Por otro lado, en Cataluña, entre 2014 y 2015 se mantuvieron contactos para traspasar los libros del fondo antiguo custodiados por la Biblioteca de Deportes a la Biblioteca de Cataluña, puesto que al primer organismo se le hacía difícil hacerse cargo de la conservación de los libros. Cuenta Eugènia Serra, directora de la Biblioteca de Cataluña, que en aquel tiempo, el Consejo Catalán de Deportes (Generalitat de Cataluña) estaba remodelando el Museo y Centro de Estudios Melcior Colet (de Barcelona), y la decisión final acerca del destino del fondo antiguo de la Biblioteca de Deportes iba ligada a esta rehabilitación" (Serra, 2016).

Actualmente, los 230 libros devueltos del antiguo fondo de la BGC se hallan depositados en la Biblioteca de Deportes de la Generalitat de Cataluña [Imagen 6]. Sin embargo, la Generalitat de Cataluña todavía no ha recibido el resto de libros, que por convenio subscrito deberían devolverse a su legítimo propietario. Por otro lado, la Generalitat de Cataluña parece haber desistido (puede que temporalmente) en el interés por la recuperación completa de las obras depositadas en Madrid. 
Por otro lado, debemos conocer que diversas obras citadas en la BGC (pero no las mismas de esta biblioteca) también pueden hallarse en los depósitos de la Biblioteca de Cataluña y de la Universidad Complutense de Madrid. Algunas de estas obras en la actualidad ya han sido incorporadas (en vista completa) en Google Books, además de otros ejemplares que pueden localizarse en la Biblioteca Digital Hispánica ${ }^{3}$.

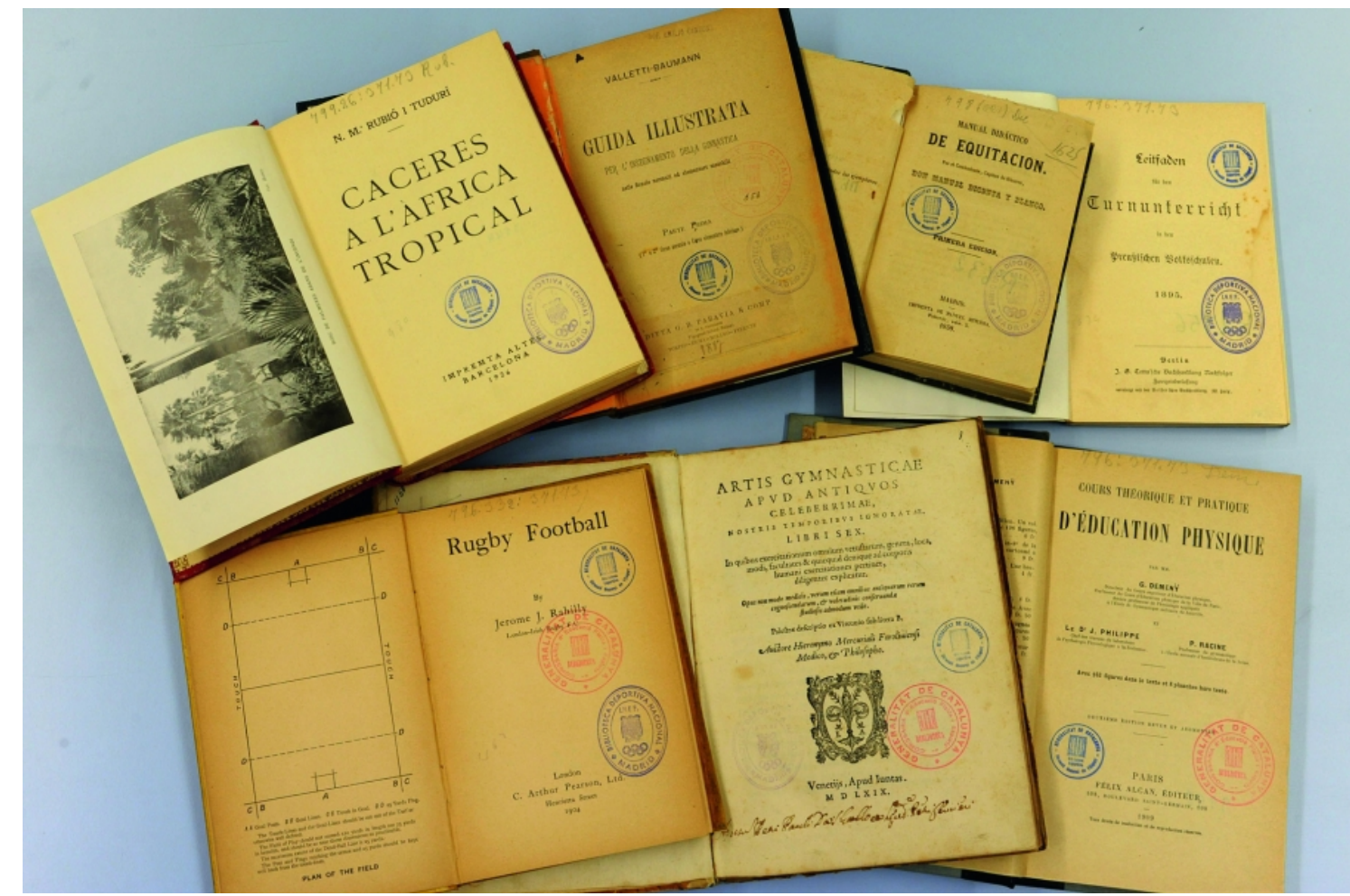

Imagen 6. Libros procedentes de la BGC con tres sellos de identificación (de propiedad o de depósito documental): Comisariado de Educación Física y Deportes, Biblioteca Deportiva Nacional, Dirección General de Deportes de la Generalitat de Cataluña. Fuente: <http://www.enciclopedia.cat/EC-EEC-1187.xml>.

\section{SOBRE EL EXTRAVÍO DE LAS OBRAS}

Desde 1983, año del primer acuerdo político de cesión de la BGC a la Generalitat de Cataluña, ya han pasado más de treinta años. Después de una primera cesión de libros, entrega parcial, todavía faltaban unas 200 obras más por entregar, entre las cuales se hallan algunas de las obras históricas más emblemáticas (Casas, 2005). Sabemos, no obstante, que bastantes obras se extraviaron por causas desconocidas. En general, esta pérdida puede atribuirse a la mala gestión y protección de la custodia del material, que finalmente pasó al fondo bibliográfico del INEF, solamente identificando 500 obras.

Como citaba el diputado Francesc Canet i Coma (ERC) "el pillaje, el descuido, el pasotismo incluso redujo este fondo de 2.000 libros a una cuarta parte, a unos 500 aproximadamente de los cuales más o menos la mitad, unos 230 , se devolvieron el año 1983 y desde entonces el proceso ha quedado paralizado" (Congreso de los Diputados, 2005b, p. 18).

Por su parte, la Oficina de Registro e Información de la Secretaría General del Consejo Superior de Deportes (2016a) mantiene, que una vez "consultado el fondo bibliográfico del Consejo Superior de Deportes, este organismo no tiene en su poder material procedente de la Comisaría de Educación Física y Deportes de la Generalitat de Cataluña”.

Sin embargo, somos de la opinión que algunas de las obras más prestigiosas citadas en 1935 por Llaverías y Palau se perdieron por el camino. Y con ello queremos decir que se extraviaron, probablemente antes, pero también después de 1939. Para conocer efectivamente qué obras fueron las adquiridas por la Generalitat de Cataluña se deberían poseer las facturas de compra y la lista de libros al detalle, pero hasta el momento no sabemos el paradero de los archivos perdidos del Comisariado de Educación Física y Deportes (El Periódico, 1986; Tixis, 1980). 
Conocemos perfectamente que algunas de estas obras perdidas por el camino o "fruto del pillaje" han sido subastadas y adquiridas por particulares, que aquí no se nos permite revelar. Prueba de ello es la imagen de una valiosa obra de Giorolano Mercuriale (1530-1606), que tan bien conocía y había estudiado Piernavieja (Torrebadella, 2014): La $3^{\text {a }}$ edición De arte gymnastica (1587) [Imagen 7].

Si en el Catálogo de la biblioteca del Gimnasio Colón se citan siete ejemplares de esta obra, cuya edición príncipe fue publicada en Venecia en 1569: Artis gymnasticae apud antiquos celeberrimae nostris temporis ignoratae, no todas están localizadas en la biblioteca de la Facultad de Ciencias de la Actividad Física y el Deporte (INEF) - Universidad Politécnica de Madrid. Las ediciones referenciadas por Llaverías son las venecianas publicadas en los años 1573, 1587, 1601 y 1644, una publicada en París de 1577, y otra en Ámsterdam de 1672, que según Piernavieja (1973b), era la mejor impresa y la más bella. Solamente la edición príncipe, de 1569 , ha sido devuelta a la Generalitat de Cataluña.

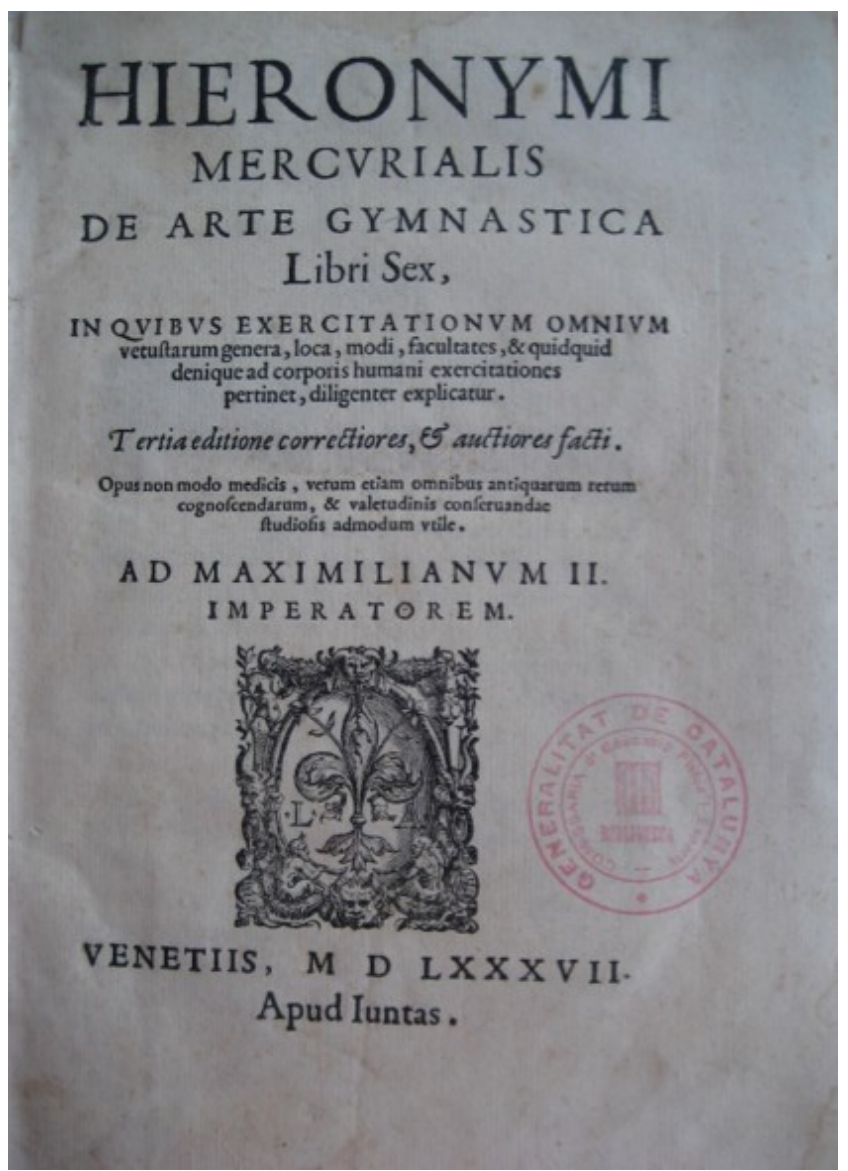

Imagen 7. Libro De arte gymnastica (1587) con el sello del Comisariado de Educación Física y Deportes. Ejemplar. Ref. BGC. Fuente: Colección privada anónima.

\section{EL CATALOGO DE LA BIBLIOTECA DEL GIMNASIO COLÓN: FUENTE IMPRESCINDIBLE PARA EL SABER DOCUMENTAL DE LA HISTORIA DE LA EDUCACIÓN FÍSICA Y EL DEPORTE}

Analizando el Catálogo de la biblioteca del Gimnasio Colón $\left(1910-1^{\mathrm{a}}\right.$ parte- y $1935-2^{\mathrm{a}}$ parte $)$ se citan en la $1^{\mathrm{a}}$ parte hasta 1910, en la sección de "Gimnasia. 1 Didáctica y literatura", 365 obras (algunas de ellas en varias ediciones). En total se recogen obras en 21 lenguas, lo cual indica el alto valor internacional de la biblioteca. La lengua con más obras es la francesa con 97 entradas; le siguen el castellano (94), el alemán (43), el inglés (24), el húngaro (15), el italiano (14), el danés (13), el sueco (10) y obras de otras lenguas (latín, portugués, holandés, danés, finlandés, bohemio, croata, polaco, rumano, ruso, serbio, búlgaro, griego, turco y japonés). Estos solamente son los registros entrados hasta 1910, que luego fueron ampliados con otros muchos más, al completarse el catálogo en 1935.

En los estudios realizados por Torrebadella (2009), como bien indica este autor, no se pudieron localizar in situ todas las obras citadas en el catálogo de Llaverías (1935). Si bien Torrebadella principalmente estudió las obras en 
torno a la educación física y el deporte más significativas publicadas en España, entre 1800 a 1935, 23 de estas obras no se pudieron localizar en ningún fondo documental. La relación de obras que marca Torrebadella sin localización (bibliotecaria o archivística) y que fueron referenciadas por Llaverías (1935), es la siguiente:

Ref. 18- Nociones de gimnástica [Amat, 1859], ref. 76- Manual de Gimnasia, Esgrima y Equitación [Castañón, 1893], ref. 99- Educación Física de la mujer (Revuelta Fernández, 1906), ref. 106- Gimnasia médica: Sus aplicaciones higiénicas, terapéuticas y ortopédicas [Fernández Gallego, 1908], ref. 367- Programa de la asignatura de teoría y práctica de la gimnasia con aparatos, construcción y designación de los más convenientes en la Escuela Central de Profesoras y Profesores de Gimnástica durante el curso de 1888-89 [Fernández Martínez, 1888], ref. 370- Programa de gimnástica higiénica [Balmes, 1892], ref. 371- Programa de gimnástica higiénica [Caballero, 1904], ref. 375- Programa de la asignatura de gimnástica higiénica y juegos corporales [Serrano, 1984], ref. 757Breve tratado de Jiu-jitsu: principales llaves de defensa que usan los más renombrados campeones de lucha japonesa [s.a., ca. 1908], ref. 803- La escuela de esgrima: Manual práctico seguido del código del duelo [Blot, ca. 1900], ref. 1088. Programa de la asignatura de teoría y práctica de la gimnasia en el Instituto Provincial de Zaragoza [Fernández, 1893], ref. 1169 bis- Programa de Gimnástica higiénica y juegos corporales. Curso primero [Pontanari, 1894], ref. 1170- Programa de educación física de $1^{\circ}$ y $2^{\circ}$ curso [posiblemente del profesor Juan Ramón Balmes, 1915], ref. 1172- Programa de la asignatura de ejercicios y juegos corporales explicados en la Escuela Normal de Maestros de Barcelona [F. F. de, 1910], ref. 1228- Memoria del Gimnasio y Sala de armas Vázquez Sampérez, calle Sisenando 7, Bienio 1892-94 [Vázquez Sampérez, 1894], ref. 1544.- Ciclismo: Datos interesantes y consejos útiles a los ciclistas [Pedal y De Flor, 1895. Obra recientemente localizada en la Biblioteca de Lambert Mata de Ripoll en Cataluña], ref. 1761- Boxeo. Reglamento. Voces técnicas [Alfaro, ca. 1920], ref. 1799- Patinar con ruedas: Apuntes para una cartilla del principiante [Celada, 1905], ref. 1859- El Alpinismo en España. Manual del alpinismo [Fernández Zabala, 1910], ref. 2009- Como se debe nadar: Reglas prácticas para aprender a nadar y poseer los estilos de natación [Cuadrada, 1921], ref. 2104- El jugador de foot-ball: Libro práctico para jugar, dirigir y presenciar partidos [Femenia, ca. 1920], ref. 2122- El problema del profesionalismo [Guardiola, 1926], ref. 2542- Juegos y recreaciones infantiles [s.a., 1906].

Por lo tanto, esto significa que por ahora estas obras se encuentran en paradero desconocido, o simplemente han dejado de existir. Hay que recordar que los libreros anticuarios catalogan estos ejemplares como "curiosos y raros", es decir, que el número de ejemplares conservados es muy reducido ${ }^{4}$. También hay aficionados y coleccionistas que van en busca de este tipo de materiales y que los adquieren en casas de subastas o en portales digitales como Iberlibro ${ }^{5}$ todocolección 6 . No obstante, en cuanto a las obras de la gimnástica, la educación física y el deporte publicadas en España, Torrebadella (2011) considera que, las más significativas referenciadas por Llaverías en 1935, prácticamente todas han sido localizadas en depósitos documentales públicos.

Por otro lado, existen otras obras del catálogo que se encuentran en paradero desconocido y que deberían ser localizadas por su inestimable valor documental y patrimonial. Nos referimos, por ejemplo, al tratado de Tuccaro Trois dialogues de l'exercice (1599, ref. 541), a los ejemplares de Mercurialis De arte gymnastica (1601, ref. 3; y 1577, ref. 5), perdidos según Palau (1982), a causa de las revueltas políticas durante la Guerra Civil. Además, echamos en falta un volumen con diferentes obras de Amorós (ref. 1025 bis), y otras muchísimas obras, prensa gimnástica y deportiva, y otros muchos documentos citados en el catálogo. Al respecto, las hipótesis de las circunstancias concretas de su pérdida pueden ser muchas, pero los que valoramos estos documentos necesitamos información.

\section{REFLEXIONES A MODO DE CONCLUSIÓN}

La biblioteca del Gimnasio Colón representa la primera biblioteca especializada gimnástico-deportiva y de la educación física de España. La confección de su catálogo es una capital aportación para los investigadores en la historia de la gimnástica, la educación física, el deporte y de otras materias afines. Gracias a la conservación parcial de esta biblioteca y de su catálogo, se ha podido avanzar y rescatar parte de la historia de la educación física y el deporte en España. Hoy, algunos de estos libros antiguos, ya digitalizados y de acceso público, han pasado a enriquecer el patrimonio bibliográfico histórico de la gimnástica y el deporte. En estos tiempos, la bibliofilia desaparece y los coleccionistas de estas obras -raros románticos del libro- no tienen interés para una modernidad líquida que desprecia todo lo que es viejo, al considerarlo caduco y obsoleto. La pérdida de valor del libro se hace destacable en las subastas y en el poco interés que despierta. Si bien es cierto que existe una cierta atracción, en tanto que oferta y demanda, para algunos, el valor sentimental puja más que el valor científico que en sí contienen estas obras. Hoy, las obras a las que nos referimos (obras antiguas sobre educación física, gimnástica y deporte), todavía se encuentran desperdigadas en diferentes fondos documentales y en colecciones privadas. No conocemos exactamente todo y cuanto realmente existe. Es por esto que deberían establecerse políticas de concierto científico y técnico (y no político) para reunir toda esta 
información en un único fondo digitalizado, permitiendo visibilizar las obras, aparte también de localizarlas in situ, restaurarlas y de proceder a su preservación.

Así pues, hay que valorar la importancia del Catálogo de la biblioteca del Gimnasio Colón cuya existencia como colección única en España estaba evidenciada y contrastada desde principios del siglo XX. Si bien en su época fue una colección limitadamente conocida, hoy apenas tiene valor más allá de unos pocos estudiosos que reconocen, como citaba Rufino Blanco (1927, p. 15), que "cualquier trabajo bibliográfico, por imperfecto que sea, alumbra el camino de la investigación científica y contribuye eficazmente de algún modo al fomento de los estudios".

La necesidad de cotejar los fondos de la Biblioteca de Deportes y los del INEF de Madrid con el Catálogo de la biblioteca del Gimnasio Colón, para conocer el estado actual de la colección es una tarea que debería re-emprenderse y cerrarse definitivamente. Por nuestra parte, hemos solicitado a la dirección de las citadas bibliotecas información sobre la existencia de las obras cuya procedencia se testifica que pertenecían a la BGC, es decir con el sello del Comisariado de Educación Física y Deportes de la Generalitat de Cataluña. Por parte de la Facultad de Ciencias de la Actividad Física y el Deporte (INEF de Madrid) - Universidad Politécnica de Madrid, se desentienden del asunto, manifestando que el responsable es el Consejo Superior de Deportes. Por el otro lado, el silencio ha sido la respuesta de la Generalitat de Cataluña (Biblioteca de Deportes), aspecto que confirma los recelos que suscita la cuestión.

Sacar a la luz la verdad y restablecer la memoria histórica de todo cuanto aconteció en la Guerra Civil, hoy todavía sigue siendo embarazoso. De todos modos, las instituciones pugnan desde los intereses políticos y partidistas por hacerse con el legado histórico de muchos bienes patrimoniales. Estas disputas se entroncan con el subyacente discurso de la nacionalización del patrimonio artístico y cultural. En este caso, la mediación no parece seguir un camino planificado.

Solamente queda sugerir y desear que la digitalización y la visibilidad pública en internet de todo lo que queda del Catálogo de la biblioteca del Gimnasio Colón fuese, a corto plazo, una realidad. Por otro lado, esto no debería desatender lo que sería pertinente, volver a reunir la biblioteca en Cataluña y centrarse en la tarea primordial de reconstruir el fondo, localizando los ejemplares perdidos.

\section{NOTAS}

${ }^{1}$ Si bien Menéndez Pelayo fue uno de los primeros teóricos, su obra no es la primera en que se valoran los estudios bibliográficos, ahí están los concursos de Bibliografía de la Biblioteca Nacional (desde 1857) y la creación de la Escuela Superior de Diplomática, en 1856, con la asignatura de Bibliografía.

${ }^{2}$ Sin embargo, precisamente es en esta época cuando el libro es estudiado, catalogado, repertoriado y coleccionado; momento que coincide con un periodo de auge de la producción editorial.

3 <http://www.bne.es/es/Catalogos/BibliotecaDigitalHispanica/Inicio/index.html>.

4 Las obras del siglo XIX y principios del XX no están demasiado controladas y es fácil que estén en bibliotecas particulares e incluso en instituciones cuyo catálogo no esté incorporado al Catálogo Colectivo del Patrimonio Bibliográfico Español.

La denominación de "curiosos y raros" por los libreros no ha de ser más que un indicio, puede ser raro en comercio, pero habitual en bibliotecas.

${ }^{5}<$ https://www.iberlibro.com>.

$6<$ http://www.todocoleccion.net $>$.

\section{BIBLIOGRAFÍA}

BERASATEGUI, M.L. Amadeo Llaverías, gimnasta i bibliòfil. Apunts. Educación física y deportes, 1998, nº 53, p. 98-102.

BERASATEGUI, M.L. Fonts bibliogràfiques per a l'estudi de l'educació física i l'esport a Cataluña (1856-1975). Temps d'Educació, 2008, no 35, p. 169-196.

BLANCO, R. Bibliografia general de la educación física: con datos copiosos referentes a la biología, antropología, anatomía, fisiología, higiene, eugénica, puericultura, paidología, pedagogía y otras ciencias fundamentales del ejercicio corporal educativo. Madrid: Hernando, 1927.

CASAS, F. Espoli a Cataluña. Biblioteca esportiva. Avui, 11 de febrero de 2005, p. 64-65.

Comissariat d'Educació Física i Esports (1937, 4 de junio). El Comissariat d'Educació Física i Esports i la Fira del Llibre. El Mundo Deportivo, p. 1.

CONGRESO DE LOS DIPUTADOS. Boletín General de las Cortes Generales. Congreso de los Diputados, 14 de octubre de 2004, Serie D: General, no 84, p. 189. 
CONGRESO DE LOS DIPUTADOS. Boletín General de las Cortes Generales. Congreso de los Diputados, 14 de enero de 2005a, Serie D: General. n 137, p. 72.

CONGRESO DE LOS DIPUTADOS. Diario de sesiones del Congreso de los Diputados, 18 de mayo de $2005 \mathrm{~b}, \mathrm{n}^{\circ}$ 288, p. 17-21.

CRUANYES, J. Els Papers de Salamanca: l'espoliació del patrimoni documental de Cataluña (1938-1939). Barcelona: Edicions 62, 2003.

CRUANYES, J. L'espoliació del patrimoni documental i bibliogràfic de Cataluña durant la Guerra Civil espanyola. Lligall, 2002, $\mathrm{n}^{\mathrm{o}} 19$, p. 35-71.

DALMAU, A.R. El circo en la vida barcelonesa. Crónica anecdótica de cien años circenses. Barcelona: Ediciones Librería Millà, 1947.

DE GREIFF, P. Informe del relator especial sobre la promoción de la verdad, la justicia, la reparación y las garantías de no repetición. Misión a España (A/HRC/27/56/Add.1) Ginebra: Naciones Unidas, 2014. Tomado de $<$ https://documents-dds-ny.un.org/doc/UNDOC/GEN/N14/564/70/PDF/N1456470.pdf?OpenElement>.

EL PERIÓDICO. El deporte se hizo oficial en Cataluña hace 50 años. El Periódico, 3 de marzo de 1986, p. 41.

FACULTAD DE CIENCIAS DE LA ACTIVIDAD FÍSICA Y DEL DEPORTE (INEF). (antonio.rivero@upm.es) (2016, 10 octubre). RE Consulta sobre los libros del Gimnasio Colón. Correo electrónico enviado a: Torrebadella Flix, Xavier (xtorreba@gmail.com)

FERRER, D. Gimnástica artística. Los Deportes, 1 de febrero de 1899, p. 35-36.

FUSTÉ, J. Breu notícia del Gimnàs de Colón de Barcelona. En: La formació inicial i permanent dels mestres, en Actes de les XIII Jornades d'Història de l'Educació als Països Catalans. Vic: Eumo, 1997, p. 243-254.

GENERALITAT DE CATALUNYA, Registre de Convenis i acords bilaterals de la Direcció General de 1'Esport, $\mathrm{n}^{\circ}$ 22. Entrada 23/11/1983, no 15956.

GUARDIOLA, R. Un bibliófilo publicó un catálogo figuerense. Ampurdan, 21 de diciembre de 1955, p. 11.

I. [Isidro Lloret]. Fragmentos de un interviú. Los Deportes, 22 de diciembre de 1906, p. 970-972.

J. LL. Siluetas. Amadeo Llaverías. Los Deportes, 14 de septiembre de 1902, p. 555-556.

LEGUINA, E. Bibliografia e historia de la esgrima española. Madrid: s.e., 1904.

LLAVERÍAS, A. Catálogo de la Biblioteca del Gimnasio Colón. Barcelona: Imp. Fiol, 1910.

LLAVERÍAS, A. Notas bibliográfico-deportivas. La Veu de l'Enpordà, 3 de febrero de 1917a, p. 3-4.

LLAVERÍAS, A. Bibliografía gimnástica. La Veu de l'Enpordà, 17 de febrero de 1917b, p. 2.

LLAVERÍAS, A. El Gimnás Colón a Figueres. La Veu de l'Enpordà, 1 de octubre de 1927, p. 5.

LLAVERÍAS, A. Discurs pronunciat per Amadeo Llaverías, Director del Gimnás Colón... Barcelona: J. Torrents y $\mathrm{C}^{\mathrm{a}}, 1896$.

LLAVERÍAS, A. Gimnasio Colón. Reglamento para el orden interior. Barcelona: Imp. Sabatel, 1901.

LLAVERÍAS, A. Al profesor D. Eusebio Ferrer y Mitayna: Palma. Los Deportes, 5 de noviembre de 1904, p. 703704.

LLAVERÍAS, A. Biblioteca del Gimnasio Colón. Catálogo de la parte pública de la misma. Los Deportes, 26 de agosto de 1905a, p. 549-555.

LLAVERÍAS, A. Gimnasio Colón. Los Deportes, 9 de septiembre de 1905b, p. 282.

LLAVERÍAS, A. Bibliografía deportiva. La Vanguardia, 5 de septiembre de 1910, p. 8.

LLAVERÍAS, A. Gimnasio Colón: Catálogo de la Biblioteca del Gimnástico - deportiva y de conocimientos afines. Barcelona: Anticuaria de Antonio Palau Dulcet, 1935.

Los Deportes. Gimnasia. Los Deportes, 1 de diciembre de 1906a, p. 894-895.

Los Deportes. Regalo a nuestros lectores. Los Deportes, 20 de octubre de 1906b, p. 734.

Los Deportes. Regalo a nuestros lectores. Los Deportes, 13 de octubre de 1906c, p. 710.

MASRIERA, A. Los buenos barceloneses: Hombres, costumbres y anécdotas de Barcelona ochocentista (1850-1870). Barcelona: Ed. Poliglota, 1924.

MENÉNDEZ, M. De Re Bibliographica. Revista Europea, 1876, vol. 8, nº 125, p. 65-73.

MERCURIALE, G. De arte gymnastica libri sex...Venetiis: Apud Iuntas, 1587.

Miscelánea. Los Deportes, 19 de agosto de 1900, p. 525.

Miscelánea. Los Deportes, 25 de agosto de 1901, p. 541.

Miscelánea. Los Deportes, 15 de octubre de 1908, p. 420.

Museo Pedagógico Nacional. Bibliografía y material de enseñanza, Educación física.-Higiene escolar. Madrid: R. Rojas, 1915.

Oficina de Registro e Información de la Secretaría General del Consejo Superior de Deportes (formularioweb@csd.gob.es) (2016a, 24 octubre). Respuesta a la información 1224. Correo electrónico enviado a: Torrebadella Flix, Xavier (xtorreba@gmail.com)

Oficina de Registro e Información de la Secretaría General del Consejo Superior de Deportes (formularioweb@csd.gob.es) (2016b, 27 octubre). Respuesta a la información 1243 asociada a la 1244. Correo electrónico enviado a: Torrebadella Flix, Xavier (xtorreba@gmail.com) 
PALAU, A. Manual del librero hispanoamericano. Tomo I. Barcelona: Agustín Palau Claveras, 1982.

PALAU, A. Llibreria Antiquaria de Antonio Palau. Catàleg núm. 27: Esgrima, Caça i Pesca, Hipisme, Jocs, Esports, Gimnástica, tauromaquia, Dansa, etc., etc., Barcelona: Imp. Ràfols, 1925.

PALAU, A. Memorias de un librero catalán, 1867-1935. Barcelona: Llibreria Catalònia, 1935.

PALOMO, A. El Gimnasio Colón. Los Deportes, 23 de diciembre de 1905, p. 833-834.

PASTOR PRADILLO, J.L. El fondo bibliográfico y documental relacionado con la actividad física y deportiva en España. Apunts. Educación física y deportes, 2008, nº 94, p. 14-22.

PIERNAVIEJA, M. Introducción. En: Mercurial, J. Arte Gimnástico (pp. I-XLII) Madrid: Instituto Nacional de Educación Física, 1973 b.

PIERNAVIEJA, M. (dir.). Catálogo de la Biblioteca Deportiva Nacional tomo I. Madrid: Delegación Nacional de Educación Física y Deportes- Instituto Nacional de Educación Física y Deporte, 1973a.

PUJADAS, X. y AUGUÉ, A. La institucionalización deportiva en plena guerra civil. La creación del Instituto de Educación Física y Deportes de Cataluña de 1937. Athlos. Revista Internacional de Ciencias Sociales de la Actividad Física, el Juego y el Deporte, 2012, n n $^{\circ}$, p. 123-143.

SÁNCHEZ MARIANA, M. Bibliófilos españoles: desde sus orígenes hasta los albores del siglo XX. Madrid: Biblioteca Nacional, 1993.

SAUDADES, J. (1921, 26 de noviembre). Llaverías y su Biblioteca. Stadium, p. 734.

SERRA, E. (BC). (eserra@bnc.cat) (2016, 27 diciembre). RE Biblioteca de 1'Esport_Consulta. Correo electrónico enviado a: Torrebadella Flix, Xavier (xtorreba@gmail.com)

SERRAMIÀ, J. La incautació documental franquista en el patrimoni català: l'acció feta al Parlament de Cataluña. Item: revista de biblioteconomia i documentació, 1997, $\mathrm{n}^{\circ}$ 21, p. 231-246.

TIXIS, P. Jo vaig enterrar l'arxiu d'esports de la Generalitat del 1936 a Sant Gregori. El Punt Diari, 15 de noviembre de 1980 , p. 3.

TORREBADELLA-FLIX, X. El Arte gimnástico-médico. Del humanismo al renacimiento de la educación física en España. Pecia Complutense, 2014, n 21, p. 21-45.

TORREBADELLA-FLIX, X. Rufino Blanco Sánchez y las fuentes bibliográficas de la educación física y el deporte en España. RICYDE. Revista Internacional de Ciencias del Deporte, 2014, $\mathrm{n}^{\circ}$ 37, p. 281-284. Doi: $10.5232 /$ ricyde2014.037.

TORREBADELLA-FLIX, X. y NOMDEDEU-RULL, A. Bibliographic Repertoire of Football in Spain (1900-1936). 121 works to interpret the social impact of football in contemporary history. Apunts. Educación Física y Deportes, 2014, no 115, p. 7-32. DOI: http://dx.doi.org/10.5672/apunts.2014-0983.cat.(2014/1).115.01.

TORREBADELLA, X. Aproximación a una historia de la actividad física y el deporte mediante el análisis de las fuentes bibliográficas (1800-1939). Apunts. Educación Física y Deportes, 2000a, no 59, p. 11-20.

TORREBADELLA, X. Contribución a la historia de la educación física en España. Estudio bio-bibliográfico en torno a la educación física y el deporte (1800-1939). Departament d'Història de l'Art i Història Social: Universitat de Lleida, 2009 [tesis doctoral].

TORREBADELLA, X. Crítica a la bibliografía gimnástica de la educación física en España (1800-1939). Anales de Documentación, 2013a, vol. 16, $\mathrm{n}^{\circ}$ 1, http://dx.doi.org/10.6018/analesdoc.16.1.158851.

TORREBADELLA, X. L'esport català durant la Segona República: el Comissariat d'Educació Física i Esports de la Generalitat de Cataluña. Barcelona: Col·legi de Llicenciats en educació Física i Ciències de l'Activitat Física i de l'Esport de Catalunya, 2000b.

TORREBADELLA, X. La Acadèmia d'Educació Física de Cataluña. Un intento por legitimar un espacio institucional y doctrinal de la educación física en la II República. Apunts. Educación Física y Deportes, 2013b, nº 114, p. 23-35. Doi 10.5672/apunts.2014-0983.cat.(2013/4).114.02.

TORREBADELLA, X. Repertorio bibliográfico inédito de la educación fisica y el deporte en España (1800-1939). Madrid: Fundación Universitaria Española, 2011.

TORREBADELLA, X. Revisión histórica de la bibliografía gimnástico-deportiva impresa en Barcelona (s. XIX1910). Biblios. Revista electrónica de bibliotecología, archivología y museología, 2016, nº 65, p. 52-69.

TORREBADELLA, X. y ARRECHEA, F. Los orígenes de una ciudad olímpica. La vida gimnástica-deportiva en la Barcelona decimonónica. Madrid: CIHEFE, 2015.

TORREBADELLA, X. y BRASÓ, J. Els textos sobre l'educació física i l'esport en llengua catalana des del 1880 fins al 1938. Llengua \& Literatura, 2018, n 28, p. 7-52. [en prensa].

TORRECILlA, Marques de la. Libros, escritos o tratados de equitación..., Madrid: Est. Tip. Sucesores de Rivadeneyra, 1921.

UHAGÓN, F. y LEGUINA, E. Estudios bibliográficos. La caza. Madrid: s.e., 1888. 